\title{
Las instituciones de la Unión Europea: su estatus, competencias y equilibrio institucional frente a la expansión
}

Ana Djoric

\section{Breve aproximación histórica de la integración europea}

La idea de la unificación europea ha sido planteada por muchas personas y no es novedosa. Podemos encontrarla tanto al Este como al Oeste, al Norte como al Sur del continente, entre los filósofos, juristas o escritores. Sin embargo, las diferencias en su enfoque impiden hasta hoy su plena ejecución. Las desigualdades ocasionaron antagonismos que llevaron a los pueblos a involucrarse en guerras sangrientas que devastaron el continente europeo. Esto planteó un grave problema en el camino de la unificación. Mantener la paz en Europa fue lo primero que se tenía que lograr para hacer realidad la concepción de los Estados Unidos de Europa.

La salvaguarda de la paz, una vez lograda, conducía en primer lugar hacia la unión económica en beneficio de todos los ciudadanos que vivían en Europa, puesto que ya se había adquirido la experiencia del fracaso de la integración política'. La unificación económica ${ }^{2}$ siempre fue el motor del proceso de unificación europea. Faltaba pues, esta-

1 El proyecto Briand, presentado en 1929 por el ministro francés ante la Asamblea General de la Sociedad de Naciones, se refería a una organización federal.

2 Robert Schuman, Ministro de Relaciones Exteriores de Francia y uno de los padres de la Europa unida, en su plan Schuman afirma: «Europa no se hará de un sólo golpe, ni en una construcción de conjunto; se hará por realizaciones concretas que en principio creen una solidaridad de hecho". El funcionalismo descarta así, tanto la integración global en beneficio de una integración por sectores, como la integración política, en beneficio de la integración económica. 
blecer un mercado común. Una vez lograda la integración económica, los pueblos europeos podían precipitarse a la búsqueda de la unidad política así como hacia el refuerzo de la cohesión social.

En la unificación europea, podemos distinguir la cooperación ${ }^{3}$ y la integración. En el modelo de cooperación, no se prevé la creación de un Estado central sino solamente, la unión de países soberanos en una confederación en la que las estructuras nacionales permanezcan inalterables. La integración va más allá de la coexistencia tradicional de los Estados nacionales. La concepción clásica de la inviolabilidad y la indivisibilidad de la soberanía de los Estados da lugar a la convicción de que sólo pueden subsanarse las imperfecciones de las relaciones entre el individuo y el Estado, las carencias de los sistemas nacionales y los abusos del poder de un Estado frente a los demás, si las diferentes soberanías nacionales se unen en una soberanía común y se fusionan a un nivel superior, en una comunidad supranacional. Este proceso debe dar como resultado la creación de un Estado federal europeo en el que los individuos confíen sus destinos a autoridades comunitarias, pero que a la vez, preserve las particularidades de las naciones que constituyan dicho Estado (federación) ${ }^{4}$.

Para un observador no informado de Europa, la unificación europea tiene una imagen confusa debido a la multiplicidad y complejidad de sus diferentes organizaciones.

En la Europa de hoy coexisten, sin un vínculo real, la Organización de Cooperación y de Desarrollo Económico (OCDE) ${ }^{5}$, La Unión de Europa Occidental (UEO) ${ }^{6}$, La Unión del Tratado del Atlántico Norte $\left(\mathrm{OTAN}^{7}\right.$, El Consejo de Europa ${ }^{8}$ y la Unión Europea.

3 El Consejo Europeo, la OCDE, así como el segundo y el tercer pilar de la UE, se constituyeron en base a este concepto.

4 La UE se fundó de acuerdo a este concepto.

5 En sus orígenes, la OCDE era la Organización Europea de Cooperación Económica (OECE), fundada el 16 de abril de 1948, creada para la repartición de la ayuda americana correspondiente al plan Marshall. En 1961, la OCDE substituyó a la OECE. Era un punto de encuentro y de negociación en lo que respecta a intercambios económicos, en el sentido del crecimiento y del libre intercambio, y también una instancia de reflexión y de análisis en torno a las economías nacionales y transnacionales.

6 Los acuerdos de París, suscritos el 23 de octubre de 1954, que entraron en vigencia el 01 de mayo de 1955, reforzaron la OTAN al instituir la UEO. Desde la iniciativa francesa para la reactivación de la UEO en 1984 (Declaración de Roma), el papel de la UEO se amplió. El Tratado de Maastricht le confirió la misión activa de mantener la seguridad. 
La Unión Europea (UE) fue creada por el tratado de Maastricht en 1992. El Tratado de la UE se compone de tres «pilares». El primer pilar se compone de tres comunidades europeas, la Comunidad Europea o, al principio, la Comunidad Económica Europea (CEE), que tiene una competencia económica y general, la Comunidad Europea de Energía Atómica (CEEA o EURATOM) y la Comunidad Europea del Carbón y del Acero (CECA), que son especializadas. El segundo pilar es el de la política exterior y de seguridad común (PESC). El tercer pilar es el de la cooperación en los ámbitos de la justicia y de los asuntos de interior (JAI). El segundo y tercer pilares representan la cooperación interestatal entre los Estados miembros y son el resultado de acuerdos tomados por unanimidad.

Las comunidades europeas se caracterizan por tres rasgos fundamentales. En principio, las comunidades europeas son, según las normas de derecho internacional, organismos internacionales. Están fundadas por tratados constitutivos. Al mismo tiempo, se trata de organis-

7 El 04 de abril de 1949, a través del Tratado del Atlántico Norte, los europeos occidentales y sus aliados norteamericanos constituyeron una organización de legítima defensa, conforme a la Carta de las Naciones Unidas. El artículo $5^{\circ}$ del tratado comprometii a los Estados miembros a ayudar al estado que podría ser atacado. Progresivamente, el tratado se plasmó en estructuras militares y se estableció una verdadera organización. Después de la disolución del Pacto de Varsovia, la OTAN se mantuvo a pesar de los camioios en Europa Oriental. Algunos estados de Europa Central deseaban ser admitidos efı la organización, sin embargo, Rusia se oponía y es así que la OTAN propone una «sociedad por la paz» en enero de 1994. El ingreso en la Sociedad implicaba el respeto de principios esenciales, la democracia, la solución negociada de conflictos y el control civil de lo militar.

8 El 19 de septiembre de 1946 en la Universidad de Zurich, Winston Churchill hizo un llamado a la reconciliación franco alemana y a formar los Estados Unidos de Europa. Del 07 al 11 de mayo de 1948, se llevó a cabo el Congreso de la Haya donde se concreta la idea de una Europa por etapas y la adopción de una Carta de los Derechos Humanos. El Consejo de Eurcpa figuraba como la organización de la Europa de las democracias; el ingreso al Consejo de Europa se vislumbraba como un nexo con Europa Occidental y un paso obligado antes de ingresar a la CEE. Para convertirse en miembro del Consejo de Europa, se tenían que respetar los derechos humanos y la democracia. Algunos países de Europa Central sólo fueron admitidos luego de que adoptaron constituciones conformes que respetaban las libertades individuales y colectivas, la democracia y el pluripartidismo.

9 Según el Artículo A: «sobre las comunidades europeas complementadas por las políticas y las formas de cooperación establecidas». 
mos regionales abiertos, de tipo especializado. La personería jurídica se confiere expresamente a cada una de las comunidades por tratado ${ }^{10}$. La especialidad de las comunidades se determina de dos maneras: en primer lugar, en su área por las comunidades sectoriales como la CECA y la CEEA luego, por su naturaleza que, para las tres comunidades, le corresponde la de organismos económicos por referencia a la noción de «mercado común». La tercera característica de las comunidades es que están fundadas en base a un modo particular de integración económica, la constitución de un "mercado común" que por sus implicancias, es susceptible de ir mucho más allá de esta única integración. La CEE fue rebautizada con el tratado que instituyó la UE, pues abandona el enfoque sectorial de las otras dos comunidades ya que su objetivo es reunir en una sola comunidad, a los Estados miembros en todos los campos de la economía. Esto se aplica a campos tan esenciales como la libre circulación de mercancías, trabajadores, servicios y capitales, así como para la libertad de establecimiento y de operaciones de pago, la política de la competencia, la política económica y monetaria, la política agrícola, la política de transportes, la política medioambiental, la política en materia de investigación y de tecnología o la política industrial.

El tema que nos interesa será el pilar comunitario: las instituciones y sus perspectivas en virtud de la expansión que se vislumbra en un futuro cercano $^{11}$.

\section{El Derecho institucional de la Unión}

El derecho institucional constituye una parte del derecho comunitario $^{12}$. Las disposiciones del derecho institucional rigen la constitución de las comunidades, su funcionamiento y su control así como el

10 Art. $6^{\circ} \mathrm{CECA}$, Art. $210^{\circ} \mathrm{CE}$, Art. $184^{\circ} \mathrm{CEEA}$

11 La UE ha iniciado el proceso de negociaciones en virtud de su expansión con trece países de los cuales diez, se convertirán en miembros de la Unión en el año 2004.

12 El derecho sustantivo y el derecho institucional son las partes que componen el derecho comunitario - Jean Boulois, Derecho institucional de la Unión Europea, París, Montchrestien, 1997; ISAAK G, Derecho comunitario general, París, Armand Colin, 1996. 
ordenamiento jurídico del que constituyen tanto la fuente como el soporte. Así pues, el derecho institucional comunitario comprende el derecho constitucional, administrativo, presupuestario, internacional o lo que normalmente denominamos, derecho público, según la concepción escolástica francesa.

\section{La estructura institucional}

En la UE se puede distinguir entre las instituciones y los órganos ${ }^{13}$.

El tratado de la CE establece una distinción entre las instituciones y los órganos. Las instituciones de la CE se enumeran en el Artículo $7^{\circ}$ (ex 4). En relación con los órganos, las instituciones disponen de menos autonomía, lo que se explica por ejemplo, en la designación de sus miembros o en el poder del que disponen para fijar su propio reglamento interno. Esta distinción que funciona entre las instituciones y los demás órganos, en la práctica, sólo tiene una importancia bastante limitada ${ }^{14}$.

En su versión original, la estructura institucional de las comunidades se basaba en cuatro instituciones: una asamblea, un consejo, una comisión y un tribunal de justicia. Las instituciones comunitarias están esencialmente encargadas de cumplir con el marco de integración definido por los Estados miembros. Al principio, se dio mayor énfasis al Consejo y a la Comisión Europea, mientras que el Parlamento Europeo ${ }^{15}$ sólo desempeñaba un papel consultivo.

Por el Tratado de fusión, suscrito el 8 de abril de 1965 y que entró en vigor el 1 de julio de 1967, se instituyeron una Comisión única y un Consejo de Ministros único para las tres comunidades en su conjunto. Las instituciones ya no eran cuatro sino cinco, después del tratado de

13 Algunos autores, como por ejemplo J. Boulois, hace la distinción entre los órganos principales y los órganos subsidiarios cuya existencia no se presenta jurídicamente de la misma manera, según haya sido o no prevista por los tratados. Ahora bien, se trata de una distinción terminológica, sin valor jurídico. (J. Boulois, Derecho institucional de la Unión Europea, París, Montchrestien, 1997).

14 Martin Zbinden, Las instituciones y los procedimientos de la toma de decisiones en la Unión Europea después de Amsterdam, Berna, Staempfli Editions SA, 2002, p. 13 y ss.

$15 \mathrm{El} \mathrm{triángulo} \mathrm{institucional.}$ 
Maastricht ${ }^{16}$. La constitución de alguna de ellas ha sido más o menos modificada, alterando así lo que fue su legitimidad fundamental.

El asunto de la repartición de competencias en el marco de la UE, se resolvió en dos ejes, horizontal y vertical ${ }^{17}$.

La repartición de competencias entre las instituciones europeas está sujeta a dos principios. El primero consiste en lo que el TJCE denomina "el equilibrio institucional» que se ha convertido en un principio general del derecho comunitario. El segundo está formado por un conjunto de normas que han tenido que ser el resultado de modificaciones que se realizaron en este equilibrio. Estas normas abordan la elección de la base jurídica de los actos en tanto que esto puede influir en la repartición de las funciones entre los órganos.

El «equilibrio de poderes» fue utilizado por el TJCE ${ }^{18}$. Se trata del principio que prevé la relación de los poderes respectivamente atribuidos a la alta autoridad y a las demás instituciones de la Comunidad. La repartición de atribuciones característica del sistema institucional comunitario, no es, en efecto, una modalidad de una separación tal y,

16 El tratado de Maastricht introdujo el Tribunal de Cuentas como la quinta institución

17 La repartición de competencias entre la Unión y sus Estados miembros debe determinar los campos y las materias en las que la primera es competente para decidir y actuar, así como los órganos hábiles para ejercer los poderes que los tratados le confieren. Los principios que abordan la repartición de competencias entre la Unión y sus Estados miembros se enuncian en el Artículo $3^{\circ} \mathrm{B}$ que cita tres principios: el principio de especialidad, el principio de subsidiariedad y el principio de proporcionalidad. La especialidad es inherente a la personería jurídica que sólo se confiere a las personas jurídicas como instrumento de realización de los objetivos en virtud de los cuales fueron creadas. Actúa como una justificación de los actos y como un límite más allá del cual la acción jurídica sin fundamento, se considerará nula y sin efectos. El principio de subsidiariedad es simple. Dispone que la comunidad y la Unión deben actuar sólo y en la medida en que los objetivos de la acción programada no puedan lograrse de manera aceptable, por una acción de los Estados miembros, y que podrían lograrse de mejor manera por una acción de la Comunidad (o de la Unión). Concierne solamente a las competencias denominadas "compartidas». La dificultad proviene pues del hecho de que no existen competencias "compartidas" o "mixtas", sino más bien, campos comunes y objetivos comunitarios. Además, el TJCE decidió que este principio no sería considerado como que tenía un efecto directo. El principio de proporcionalidad determina que la acción de la comunidad no sobrepase lo necesario para alcanzar los objetivos del tratado. En la práctica del TJCE, este principio ha alcanzado valor de principio general.

18 Fallo Meroni, 13/06/1958, ${ }^{\circ}$ 9/56, p. 11 
sólo podría llegar a serlo por esta razón que las instituciones no proceden de una misma legitimidad.

Los actos de las instituciones deben estar fundados en los artículos de los tratados que constituyen su base legal; esto no sólo condiciona la naturaleza del acto que pueden realizar las instituciones sino que también condiciona su contenido y su procedimiento de promulgación. La hipótesis de una ausencia de base legal específica está regulada por los artículos de los tratados. El procedimiento aplicable se caracteriza especialmente por el hecho de que el Consejo debe resolver por unanimidad y que, según las disposiciones de los tratados de la $\mathrm{CE}$ y la CEEA, al Parlamento Europeo sólo se le consulta.

\section{Las Instituciones Legislativas}

\subsection{El Parlamento Europeo}

El Parlamento Europeo (PE) ${ }^{19}$ está compuesto por los representantes de los pueblos de los Estados reunidos en las comunidades.

Estaba previsto que estos representantes fuesen elegidos por sufragio universal directo según un procedimiento uniforme en los Estados miembros. Sin embargo, hasta 1979, los miembros del PE eran miembros delegados de los parlamentos nacionales. No obstante, desde ese año y desde las primeras elecciones por sufragio universal directo, el Parlamento es el órgano de expresión democrática, en el sentido propio del término.

La constitución del Parlamento está regulada por tres series de disposiciones, unas de las cuales se relacionan con su composición, otras con la elección y las últimas con el estatus de sus miembros.

El mandato de los diputados es incompatible con la calidad de miembro del gobierno de un Estado miembro. Ahora bien, es compatible con el mandato parlamentario nacional.

19 Debido a la creación de la CECA, la Asamblea Común fue instiruida como órgano parlamentario. Desde la creación de la CEE y de la CEEA, sus competencias se han ampliado a estas nuevas comunidades. En 1962, se le dio la denominación de Parlamento Europeo. No obstante, esta denominación en tró en los tratados constitutivos sólo por el AUE. 
La organización y el funcionamiento del Parlamento se rigen por disposiciones que, establecidas en su mayor parte en su reglamento interno, reproducen las soluciones habituales del derecho parlamentario.

El Parlamento tiene su sede en Estrasburgo, donde se llevan a cabo los doce períodos de sesiones plenarias mensuales, incluyendo la sesión relacionada con el presupuesto. Los períodos de sesiones plenarias adicionales se llevan a cabo en Bruselas. Las comisiones del Parlamento Europeo tienen su sede en Bruselas. La Secretaría General del Parlamento Europeo y sus servicios permanecen instalados en Luxemburgo.

En el procedimiento legislativo, el papel del Parlamento evoluciona. Los tratados han cambiado considerablemente el papel y las competencias del Parlamento. Su influencia en el proceso legislativo aumentó sobre todo después del tratado sobre la UE que modificó ostensiblemente su situación. Sus poderes se han ampliado progresivamente. Al principio, estaba previsto que el Parlamento tenía que ser consultado. Su decisión no podía influir el trabajo del Consejo pues su dictamen no era obligatorio. Sin embargo, la situación cambió. En 1975 se introdujo el procedimiento de concertación que concedía al PE verdaderos derechos de participación. La consecuencia: el PE puede ser aprovechado para los proyectos de actos legislativos que tienen consecuencias notables para el presupuesto comunitario. Desde 1975, el PE goza de facultades importantes y de verdaderos derechos de codecisión en materia de derecho presupuestario.

Desde la entrada en vigencia del Acta Única Europea (AU), los acuerdos de adhesión y asociación con otros Estados requieren de la aprobación del PE. Una reglamentación diferenciada rige los otros acuerdos internacionales.

El Acta Única, luego el tratado sobre la UE, introdujeron en principio, un dictamen conforme sobre cierto número de casos; además, se inició la ejecución de los procedimientos de cooperación. Así, adquiere cada vez más competencias. La consulta del Parlamento señala el cambio en la repartición de poderes. Con el tratado sobre la Unión que entró en vigencia a fines de 1993, el procedimiento legislativo más importante viene a ser el procedimiento de codecisión que se vuelve a introducir. Éste rige un buen número de grandes campos del pilar comunitario tales como el mercado interior, la cultura, la educación, la salud, la investigación y el medio ambiente. La codecisión confiere 
al PE verdaderas facultades de codecisión, en realidad, de colegislador, al lado del Consejo. Sin embargo, es el tratado de Amsterdam el que hace desaparecer el procedimiento de cooperación en beneficio de la codecisión. No obstante, se debe recalcar que, a diferencia de los parlamentos nacionales, el PE no siempre ha gozado de la iniciativa legislativa.

El PE puede deliberar sobre cualquier asunto relacionado con la UE y emitir su dictamen. Los dictámenes del PE no comprometen a las demás instituciones.

El PE puede plantear temas a nivel oral o escrito, y las demás instituciones deben responder a ellos.

En la hipótesis que exista consulta obligatoria, estamos ante la presencia de un sistema de codecisión. Un acto que no está acompañado del dictamen positivo ${ }^{20}$ necesario, es inválido y nulo, no por un vicio de forma sino de incompetencia.

Además, existe la segunda hipótesis - aquella en la que la consulta obligatoria es seguida por un dictamen facultativo.

El Parlamento tiene una misión de control. Cada año, la Comisión presenta el informe anual así como el cronograma de trabajo para el año siguiente. Cada año, el Consejo rinde cuentas sobre el desarrollo de la UE.

El Parlamento puede expresarse de manera tal que obligue a la Comisión a renunciar. En este caso, hablamos de una moción de censura $^{21}$.

En la actualidad, el PE comprende 626 miembros. El tratado de Amsterdam introdujo, a propuesta del mismo PE, el límite superior de 700 diputados en el PE.

El Parlamento puede presentar una acción ante el TJCE. Puede presentar un recurso por omisión en contra de otras instituciones comunitarias en el caso de que éstas dejen de cumplir con sus obligaciones de acuerdo a los tratados.

20 El dictamen positivo se exige en los siguientes campos: derechos vinculados con la ciudadanía, atribución de misiones específicas al BCE, modificación del estatuto del BCE, organización y funcionamiento de los fondos con fines estructurales, conclusión de los acuerdos de asociación.

21 La más conocida de las mociones de censura fue la de 1999 cuando la Comisión se vio obligada a dimitir el 15 de marzo de dicho año. 
Por su parte, los ciudadanos, pueden someter, bajo forma de peticiones, sus demandas o reclamos a la Comisión de Peticiones del PE. El PE está igualmente informado por el Defensor del pueblo europeo.

El PE supervisa el nombramiento del Presidente de la Comisión así como la Comisión en su conjunto, requiere de la aprobación del PE.

\subsection{El Consejo de la Unión Europea (Consejo de Ministros)}

Antes de abordar la explicación de los problemas de fondo, se deben explicar ciertos puntos que pueden causar confusión. El Consejo de la UE o el Consejo de Ministros no es el Consejo Europeo ${ }^{22}$. Se trata de dos instituciones diferentes. Además, debemos desconfiar de cualquier parecido con el Consejo de Europa que permanece fuera de la UE, a pesar del hecho de que es muy frecuente asimilarlo con esta integración europea, más aún que el camino hacia la UE pasa por el Consejo de Europa ${ }^{23}$.

El Consejo de la Unión Europea ${ }^{24}$ y el Consejo Europeo son las instituciones comunitarias donde se negocia el equilibrio entre los intereses de cada Estado miembro y el interés comunitario. Los intereses particulares de los Estados miembros son defendidos por las delegaciones gubernamentales de dichos Estados.

El Consejo se presentaba en el sistema institucional comunitario como la institución representativa de los Estados miembros. Se trata

22 El Consejo está subordinado políticamente al Consejo Europeo que está compuesto por los Jefes de Estado y de Gobierno así como por los ministros de relaciones exteriores. Es frecuente plantear el asunto relacionado con el Consejo Europeo y su relación con el Consejo. ¿Se puede considerar como una formación del Consejo? Esta pregunta no es nueva. Algunas disposiciones emanadas del tratado sobre la UE mencionan al Consejo “reunido a nivel de los Jefes de Estado o de Gobierno" sin embargo, aún la práctica más reciente, demuestra que el Consejo Europeo no se circunscribe a tomar decisiones de tipo político, sino también a tomar verdaderas decisiones jurídicas.

23 Solamente el país que es miembro del Consejo de Europa puede convertirse en candidato para ingresar en la UE.

24 Antes de la entrada en vigencia del tratado de la UE, la denominación oficial del Consejo era «Consejo de las Comunidades Europeas». Por decisión del Consejo del 8 de noviembre de 1993, esta denominación fue reemplazada por "Consejo de la UE». No obstante, podríamos hablar también de los Consejos de la UE pues existen actualmente, veinticuatro formaciones diferentes del Consejo. 
de un órgano intergubernamental depositario de la legitimidad estatal. Sus competencias se han extendido más allá del campo propiamente comunitario y del hecho del papel que le corresponde al Consejo Europeo.

El Consejo, en cuanto a su composición y funcionamiento, se rige en parte, por las disposiciones de los tratados y en parte, por un reglamento interno. Desde 1993, se le denomina "Consejo de la Unión Europea ${ }^{25} \mathrm{y}$ es designado como tal en todas las acciones que apruebe incluidas en el marco de la política exterior y de seguridad común y en el marco de la cooperación en los asuntos de interior.

La estructura interna del Consejo se compone, de manera horizontal, por un Consejo de Asuntos Generales y por Consejos Especializados, y de manera vertical, por tres niveles de trabajo: nivel ministerial $^{26}$, nivel de representantes permanentes ${ }^{27}$ y nivel de los grupos de trabajo ${ }^{28}$.

El Consejo está formado por un representante de cada Estado miembro a nivel ministerial, facultado para comprometer al gobierno de dicho Estado. Por consiguiente, sólo las personas que ostenten la calidad de miembro del gobierno de un Estado, pueden ocupar un escaño en el Consejo, excluyendo cualquier otra función y en particular, la de los funcionarios, cualquiera que sea su rango. Además, la estructura del Consejo podía diversificarse en formaciones según la correspondencia entre las atribuciones propias de cada miembro de los gobiernos nacionales, por un lado, y los asuntos de la agenda del día, por otro lado. Finalmente, este texto no dejaba de fundamentar la unidad de la institución.

25 Decisión 93/591, J.O. $\mathrm{n}^{\circ} \mathrm{L} 281$ del 16 de noviembre de 1993, p. 18

26 A nivel ministerial, el Consejo se reúne ya sea como Consejo de Asuntos Generales o como Consejo Ministerial Especializado.

27 Los representantes permanentes de los Estados miembros (los embajadores acreditados ante la UE) constituyen un comité que representa el nivel de trabajo intermediario del Consejo. Este Consejo es denominado con mayor frecuencia como COREPER. En un principio, estaba compuesto por un solo representante permanente por Estado miembro así como por un representante de la Comisión.

28 Para los acuerdos y las negociaciones técnicas propiamente dichas. Los grupos de trabajo están compuestos por funcionarios especializados de los ministerios nacionales; la Comisión está representada al mismo nivel. La mayor parte de los grupos de trabajo se forman para una labor muy precisa. Los grupos de trabajo sólo pueden deliberar de una manera claramente delimitada y son disueltos al finalizar el procedimiento. 
El Consejo se reúne en formaciones de composición y de competencia técnica diferentes.

El Consejo tiene su sede en Bruselas. Durante los meses de abril, junio y octubre, lleva a cabo sus sesiones en Luxemburgo.

La presidencia está garantizada para cada Estado miembro durante seis meses según una orden establecida por los tratados ${ }^{29}$. Según una decisión del Consejo Europeo de Bruselas (diciembre de 1993), esta disposición debía ser modificada en la perspectiva de las nuevas adhesiones. El orden de rotación de la presidencia, siempre semestral, fue fijado en adelante por el Consejo que resolvió por unanimidad. Lo mismo sucede con el Consejo Europeo cuya presidencia es garantizada de la misma manera ${ }^{30}$.

Para cada sesión, el presidente establece una agenda provisional que es enviada a los miembros del Consejo y a la Comisión, por lo menos con catorce días de anticipación antes del inicio de la sesión.

El poder de decisión o el poder de determinar las acciones apremiantes, fue distribuido por los tratados entre la Comisión y el Consejo. Ahora bien, a partir de las revisiones de los tratados constitutivos, podemos hablar quizá de un triángulo instituciona ${ }^{31}$.

Para la toma de decisiones del Consejo, el tratado de la CE prevé en principio, tres reglas de votación: por unanimidad, por mayoría calificada y por mayoría simple.

En la primera hipótesis, el tratado exige la unanimidad, es decir, los votos de todos los miembros del Consejo. La segunda hipótesis es la de los dictámenes conformes. El dictamen es considerado como aprobado si la propuesta de la Comisión recibe el acuerdo de la mayoría absoluta de los representantes de los Estados miembros. Si, por el con-

29 Actualmente Dinamarca está a cargo de la Presidencia. Según la agenda, se prevé que en el año 2003, dicha presidencia del Consejo recaiga en Grecia (del $1^{\circ}$ de enero al 30 de junio) y en Italia (del $1^{\circ}$ de julio al 31 de diciembre).

30 La presidencia tiene una gran importancia para el trabajo del Consejo. Ejercer las funciones de la presidencia significa un gran prestigio político. Sin embargo, el prestigio no es la única consecuencia. El Estado miembro que preside está encargado de determinar las sesiones, establecer la agenda. Así como las prioridades políticas influyen en el ritmo de la evolución de la integración europea debido al sistema de rotación, por consiguiente, los problemas prioritarios que se deben resolver cambian prácticamente cada seis meses. Es probable que este sistema sea modificado en virtud de la expansión.

31 La Comisión, el Consejo y el Parlamento. 
trario, el tratado no impone ni la unanimidad ni la mayoría calificada, las decisiones se toman por mayoría absoluta de los miembros que componen el Consejo.

Los votos de los miembros del Consejo son afectados por una ponderación de votos. Esto significa que los votos de los Estados miembros se ven afectados por un coeficiente de ponderación. El límite mínimo de obtención de mayoría calificada está establecido en aproximadamente $71 \%$ del total de votos. El número de votos suficientes para evitar alcanzar la mayoría calificada es denominado minoría de bloqueo. El número de votos que constituyen la mayoría calificada varía según se trate que el Consejo vaya a resolver sobre una propuesta de la Comisión o de otros casos, Cuando el Consejo resuelve sobre una propuesta de la Comisión, los acuerdos se aprueban si obtienen 62 votos.

El Consejo o los representantes de los Estados miembros designan, entre otros, a los miembros de la Comisión, del TJCE, del TPI y de la CC.

El Consejo tiene la facultad de suscribir tratados internacionales en nombre de la Comunidad y representa a la Comunidad en el exterior.

El Consejo sólo puede distanciarse de la propuesta de la Comisión si lo resuelve por unanimidad.

\subsection{El Consejo Europeo}

El Consejo Europeo nació de la práctica de las cumbres de los Jefes de Estado o de Gobierno (Cumbres Europeas). En 1974, se decidió que esta cumbre se llevaría a cabo regularmente en el futuro, bajo la apelación de "Consejo Europeo". Para el AU, el Consejo Europeo es consagrado por primera vez en los tratados comunitarios y, en el tratado sobre la UE, se le confiere un conjunto de labores más claramente definido.

La labor principal del Consejo Europeo es brindar los impulsos políticos necesarios a las actividades de la Unión así como fijar las orientaciones y objetivos políticos generales. Puede tomar algunas decisiones.

Puede ejercer una cierta función de coordinación, especialmente en relación con las diversas formaciones del Consejo de la UE o de las políticas que se deben seguir en el seno de los diferentes pilares de la UE.

En lo que concierne a las decisiones del Consejo Europeo, se debe señalar que los procedimientos de votación no son objeto de una regla- 
mentación clara. En general, los documentos, tales como las declaraciones y conclusiones de la presidencia, son aprobados por consenso, Sin embargo, también existen casos, especialmente durante la convocatoria a las conferencias intergubernamentales, donde por analogía con el Consejo de la UE, las normas de votación de esta última, se han aplicado.

\subsection{La Comisión Europea}

Desde $1967^{32}$, la Comisión designa la institución de las comunidades que, según los autores de los tratados constitutivos, estaba destinada a representar a cada Comunidad como tal, a definir y promover el interés común, independientemente de los componentes estatales de sus organizaciones. El tratado sobre la Unión ha modificado ostensiblemente su situación colocándola en una cierta dependencia con respecto al Parlamento Europeo.

Los tratados establecen la composición de la Comisión ${ }^{33}$. La organización de la Comisión reproduce el modelo de una estructura de tipo gubernamental que tiene un colegio, miembros, servicios y órganos auxiliares.

La Comisión consta de una secretaría general, bajo la autoridad de un secretario general cuyo papel es bastante amplio.

La Comisión dispone de un conjunto de servicios que forman una única administración. Estos servicios están estructurados en direcciones generales y servicios asimilados, articulados a su vez en direcciones, y éstas, en unidades. Puede constituir estructuras temporales, de grupos de trabajo y diferentes comités.

La Comisión está compuesta por diecisiete miembros elegidos en virtud de sus competencias generales y que ofrecen todas las garantías en cuanto a independencia. El Consejo, por unanimidad, puede modificar este personal, precisándose además que sólo los nacionales de los Estados miembros pueden ser miembros de la Comisión y que ésta debe comprender, por lo menos, un nacional de cada uno de los Estados miembros, sin que el número de miembros que tengan la naciona-

32 Antes existía la Alta Autoridad, determinada por cada uno de los tratados constitutivos.

33 Art. $157^{\circ} \mathrm{CE}$, Art. $9^{\circ} \mathrm{CECA}$, Art. $126^{\circ} \mathrm{CEEA}$. 
lidad de un solo Estado sea superior a diez. El Consejo Europeo de Bruselas estableció su personal en veintiuno al añadir a cuatro nuevos miembros, uno por cada Estado nuevo. El retiro de Noruega disminuyó la cifra de este personal a veinte $(5 \times 2+10 \times 1)$.

Los miembros de la Comisión son nombrados por un mandato renovable de cinco años. Deben ejercer su actividad con total independencia, especialmente, con relación a sus países y sus gobiernos y deben velar por el interés general de la CE. No deben solicitar ni aceptar instrucciones de los gobiernos o de otros organismos. Los Estados miembros no deben tratar de influir en los miembros de la Comisión ${ }^{34}$.

Independientemente del fallecimiento de algún miembro, el mandato podrá recortarse ya sea de manera colectiva, mediante la aprobación de una moción de censura por parte del Parlamento Europeo o, de manera individual, luego de una renuncia voluntaria o una destitución del cargo.

En caso de fallecimiento o renuncia del presidente, éste será reemplazado por el resto de su mandato, según el procedimiento general.

Las funciones de los miembros de la Comisión son evidentemente incompatibles con cualquier otra actividad, remunerada o no.

En caso de incumplimiento de obligaciones, el Tribunal de Justicia, informado por el Consejo o por la Comisión, puede pronunciar la destitución del cargo o la inhabilitación del derecho a pensión del interesado o de otras ventajas que le correspondan, según sea el caso.

En el procedimiento legislativo, la Comisión tiene un monopolio de iniciativa. "La Comisión propone, el Consejo dispone». El modo normal de la expresión de iniciativa es la propuesta. Ahora bien, no es el único modo. Es posible que las demandas del TJCE se conviertan en el punto de partida o de inicio de los procedimientos que den lugar a una recomendación. Además, el Parlamento Europeo, por mayoría de sus miembros, puede solicitar a la Comisión someter cualquier propuesta adecuada sobre los asuntos que considere requieran la elaboración de un acta comunitaria para la ejecución del tratado. Así pues, el Consejo y el Parlamento pueden invitar a la Comisión a someterles una propuesta de acto jurídico, sin embargo, esto no tiene ningún efecto jurídicamente obligatorio para la Comisión. El objetivo de esta elaboración es que la Comisión actúe como un filtro independiente con el 
fin de no llenar la agenda política comunitaria, con una multiplicidad de iniciativas que sólo obedecen a la lógica de intereses nacionales.

En el ejercicio de sus competencias, la Comisión está únicamente encargada de velar por el interés comunitario. En el seno del Consejo, siempre está representada así como en todos los niveles de trabajo del Consejo. No tiene derecho a voto pero dispone del derecho de ser entendedora.

El papel de la Comisión como representante del interés comunitario es particularmente importante al momento de las decisiones por mayoría en el seno del Consejo: la conformidad del acto jurídico con la propuesta de la Comisión garantizan, al menos en minoría, que el interés comunitario sea considerado como respetado por la Comisión.

La Comisión supervisa que otras instituciones y los Estados miembros cumplan con las obligaciones que se desprenden del derecho comunitario ${ }^{35}$. Es por ello que se le denomina la garante de los tratados.

La Comisión sólo posee facultades de ejecución propias en el campo de la competencia, las ayudas otorgadas por los estados y en los campos que estaban cubiertos por el tratado de la CECA.

La Comisión establece el anteproyecto del presupuesto que es decidido en última instancia por el Consejo y el Parlamento. Igualmente, está encargada en gran parte de su buena ejecución.

La Comisión representa a la Comunidad ante los Estados miembros, terceros países y organizaciones internacionales. Posee sus propias representaciones en todos los Estados miembros, así como delegaciones en un centenar de países en el mundo y ante numerosas organizaciones internacionales.

\section{Los Organismos de Control}

Con el fin de que la integración pueda convertirse en una realidad efectiva, son indispensables mecanismos con miras a garantizar la aplica-

35 La Comisión puede presentar ante el TJCE un procedimiento por incumplimiento de un Estado, un recurso de nulidad o un recurso por omisión o actuar contra las infracciones del derecho comunitario cometidas por el Consejo, el Parlamento, el Instituto Monetario o el BCE. En ciertos campos, puede igualmente actuar contra las infracciones cometidas por personas naturales o jurídicas, por ejemplo, en el marco del derecho a la competencia. 
ción e interpretación uniforme del derecho comunitario. Esta reflexión da como resultado, desde la creación de la CECA, la constitución de un Tribunal de Justicia con una estructura supranacional e independiente de los Estados miembros. Igualmente, la cooperación de los diferentes órganos comunitarios así como la repartición de las competencias entre estos y el nivel comunitario y los Estados miembros, hicieron parecer adecuada la posibilidad de recurrir a una instancia judicial obligatoria. Al Tribunal de Justicia, se atribuyeron igualmente las competencias que le correspondían. Al momento de la creación de la CEE y de la CEEA, en lugar de constituir tribunales separados, se decidió ampliar las competencias del Tribunal existente en las nuevas comunidades. Este Tribunal se convirtió así, en el Tribunal de Justicia de las comunidades europeas, denominado igualmente Tribunal Europeo de Justicia ${ }^{36}$.

\subsection{El Tribunal de Justicia de las Comunidades Europeas}

El TJCE estaba previsto en la estructura original de las instituciones, sin embargo, no es el caso del Tribunal de Primera Instancia, establecido por el Acta Única. El TPI fue efectivamente instituido por una decisión en $1988^{37}$.

El TJCE está compuesto por jueces y por abogados generales. Cuenta con un secretario judicial que es ayudado por asistentes.

Al principio, el TJCE estaba formado por trece jueces. Este número fue el resultado final de las actas de adhesión de España y Portugal, ilustrando la práctica según la cual, cada adhesión conlleva al aumento del efectivo de los jueces, de manera que se permita a los nuevos Estados miembros contar con uno de sus nacionales en el Tribunal.

Los jueces y los abogados generales son elegidos entre las personalidades que ofrecen todas las garantías de independencia y que reúnen las condiciones requeridas para el ejercicio en su país, de las más altas funciones jurisdiccionales o, son jurisconsultos con competencias notables. La designación se hace de común acuerdo entre los gobiernos

36 Art. $220^{\circ}$ (ex 1640) TCE en 245 (ex 188 ${ }^{\circ}$ ) así como el Protocolo $\mathrm{N}^{\circ} 11$ (ex B) TCE que incluye el estatuto del TEJ

37 Decisión $88 / 591$ del Consejo del 24 de octubre de 1988. JO N L 319 del 25 de noviembre de 1988. 
de los Estados miembros, de manera que si los jueces y abogados generales han sido bien presentados por su Estado de nacionalidad, no le deben a éste su designación pues ésta es colectiva.

El mandato es de seis años, con una renovación parcial cada tres años. Existe la posibilidad de renovación del mandato.

Las funciones del juez y las del abogado general están sometidas a cierto número de incompatibilidades destinadas a garantizar la independencia de sus titulares. Están especialmente prohibidos de ejercer cualquier función pública o administrativa así como toda actividad profesional, remunerada o no, salvo, en este segundo caso, el permiso excepcional que, por ejemplo, puede relacionarse con las funciones de enseñanza.

$\mathrm{Al}$ momento de ocupar sus cargos, los jueces y abogados generales prestan juramento. Se benefician de inmunidad diplomática que incluso se extiende hasta después de la finalización de su mandato y que sólo el Tribunal de Justicia puede levantar. No puede privárseles de sus funciones ni despojárseles de sus prerrogativas inherentes a no ser que sea a través de una sentencia unánime del Tribunal, que falla sin la presencia del interesado. El Tribunal establece su estatuto.

Esencialmente, existen seis tipos de procedimientos ante el TJCE: el procedimiento por incumplimiento, el recurso de nulidad, el recurso por omisión, la acción de indemnización, el procedimiento de cuestión prejudicial y el dictamen.

Con relación a la UE considerada en su conjunto, el TJCE, después de la entrada en vigencia del tratado de Maastricht, sólo era competente para el pilar comunitario y las disposiciones finales.

El tratado de Amsterdam amplió considerablemente las competencias del TJCE especialmente, con el fin de reforzar la protección de los derechos humanos y las libertades fundamentales en la UE, así como ciertos asuntos que provenían del tercer pilar de la UE. Esto vinculaba ya desde antes a la Unión, considerando que el Art. $6^{\circ}$ (ex F) TUE hacía referencia explícit al Convenio Europeo sobre los Derechos Humanos. Por el tratado de Amsterdam, el Art. $46^{\circ}$ (ex Art. L) fue modificado con el fin de que los órganos de la UE sometan el respeto de los derechos humanos y de las libertades fundamentales a la jurisprudencia del TJCE. Además, las nuevas disposiciones sobre la cooperación reforzada están sujetas al control del TJCE. 


\subsection{El Tribunal de Primera Instancia}

Como medida para reducir la carga laboral del TJCE, se formó, en 1988, el Tribunal que resuelve en primera instancia ciertos tipos de litigio.

El TPI se encarga de los recursos presentados en el marco del derecho de la función pública, del derecho a la competencia, en el campo del carbón y del acero, así como de todos los recursos directos de personas naturales y jurídicas, contra alguna institución comunitaria (salvo los recursos presentados en el marco del derecho antidumping). Una sentencia del TPI puede ser objeto de un recurso ante el TJCE.

\subsection{El Tribunal de Cuentas}

El Tribunal de Cuentas figura entre las instituciones en la lista que brindan los tratados de las comunidades europeas, desde el tratado sobre la Unión.

Fue creado por el tratado del 22 de julio de 1975. Su reconocimiento estuvo destinado a reforzar la autoridad.

El Tribunal de Cuentas está encargado del control de cuentas. No es una institución jurisdiccional. Tiene su sede en Luxemburgo.

Los miembros del Tribunal, durante el ejercicio de sus funciones, no pueden ejercer otra actividad profesional, remunerada o no.

Los miembros del Tribural sólo pueden ser relevados de sus funciones o despojados del derecho a pensión o del derecho a otros beneficios que le corresponden, si el Tribunal de Justicia comprueba, a solicitud del Tribunal de Cuentas, que han dejado de responder a las condiciones requeridas o han dejado de satisfacer las obligaciones inherentes a su cargo. La renuncia voluntaria o destitución tel cargo son posibles.

El Tribunal de Cuentas tiene por misión, examinar la legalidad y la regularidad de las partidas y los gastos de la Comunidad así como hacer respetar los criterios de una buena gestión financiera. El Tribunal de Cuentas decide en completa libertad en los campos que somete a un control más detallado.

El Tribunal de Cuentas puede controlar los organismos que dependen de los Estados miembros y de las empresas y personas privadas, en la 
medida en que se trate de verificar la utilización de las subvenciones de la $\mathrm{CE}$, conforme al derecho comunitario. Este trabajo lo realiza en colaboración con las autoridades de control nacionales.

El Tribunal de Cuentas está autorizado para adoptar posiciones en el marco de ciertos procedimientos de decisión. Es el caso por ejemplo, de las propuestas de modificación de los reglamentos financieros del presupuesto comunitario o, de las propuestas que aborden el tema de la lucha contra el fraude.

\section{La necesidad de la reforma de las instituciones de la UE}

La expansión de la Unión Europea y la adhesión de nuevos Estados plantean nuevos problemas. La necesidad de reforma es evidente, considerando que la estructura existente ya ha demostrado ciertas carencias en la práctica. Si no pueden administrar los intereses de los quince Estados miembros en la actualidad, es difícil imaginar que en el futuro podrán lograrlo para 25 (27 ó 28).

Las primeras ideas de reforma vieron la luz al momento de los trabajos preparatorios para la conferencia intergubernamental (CIG) del tratado de Amsterdam. En aquella época, la conclusión fue que se tenían que reforzar las instituciones. La reforma institucional sobreentiende la modificación del procedimiento legislativo. Se tienen que multiplicar los casos de toma de decisiones por mayoría y disminuir los casos de toma de decisiones por unanimidad. De esta forma, se reforzará el papel del Parlamento. Sin embargo, se considera que el monopolio de iniciativa será muy difícil de transferir de la Comisión al Parlamento.

Las instituciones legislativas deben modificar su tamaño. Al mismo tiempo, se tiene que limitar el número de comisionados en la Comisión, la ponderación de votos en el seno del Consejo y el número de diputados en el Parlamento. Es un asunto difícil de gestionar si los Estados miembros no desean renunciar a sus prioridades nacionales. Somos testigos de una nueva fase de evolución de la UE. La afirmación del papel de las naciones en el seno de las estructuras comunitarias lleva a la confederación. Los trabajos sobre el Convenio continúan y deben llevar al acuerdo en la próxima CIG, prevista para el año 2004.

Durante la última cumbre del Consejo Europeo en Sevilla, el 21 y 22 
de junio de 2002, el acuerdo relacionado con la reforma del Consejo salió a la luz. En efecto, se perciben modificaciones múltiples, relacionadas con el Consejo de Ministros y el Consejo Europeo. Sin embargo, nos queda una impresión de una reforma más bien técnica, pues no es un acuerdo sobre los asuntos de fondo, tales como las competencias, la ponderación de votos, la representación de los Estados, las decisiones que se tienen que tomar por mayoría calificada en lugar de por unanimidad.

Este año se vislumbra difícil. Diversas reformas y diversas reuniones importantes figuraban en la agenda de la UE. Sin embargo, las elecciones en Alemania han retrasado el proceso de negociaciones. En los próximos meses se dará respuesta a ciertas preguntas. No obstante, se tendrá que esperar aún un poco más para la reforma institucional.

La expansión de la Unión y la adhesión de los primeros Estados estaba prevista para el año 2004. Antes de dicha fecha, las instituciones europeas deben estar preparadas para la Europa de los veinticinco. 